\title{
Anfassen und erleben
}

Liebe Leserinnen, liebe Leser,

ob und wann man sich beispielsweise in einem Nutzfahrzeug wohlfühlt, hängt von jedem persönlich ab. So stellt sich bei manchen während des Fahrens in einem modernen Lkw aufgrund der vielen Assistenzsysteme schnell ein angenehmes und sicheres Fahrgefühl ein. Andere benötigen dagegen bestimmte Komfortfunktionen an dem mobilen Arbeitsplatz, um sich wohlzufühlen.

Das Anfassen und Erleben ist auch in der Nutzfahrzeugindustrie für OEMs und Zulieferer ein wichtiger Verkaufsfaktor. In Zeiten von Covid-19 wird dies allerdings erschwert. So wurden viele Großveranstaltungen auch im Herbst - für manchen die schönste Jahreszeit - von den Verantwortlichen aus Sicherheitsgründen abgesagt. Und auch für den kommenden Winter sieht es derzeit nicht nach einer Besserung aus - ganz im Gegenteil. Dabei ist gerade das persönliche Gespräch auf einer Messe direkt an dem Produkt oftmals der entscheidende Impuls zum Erteilen eines Kaufauftrags.

Auch wir Journalisten „leben“ vom persönlichen Kontakt und Gespräch. Viele Neuigkeiten und Trends erfährt man erst auf diese Weise. Einige Unternehmen versuchen nun, Vor-Ort-Pressekonferenzen - die unter anderem auf Messen stattfanden - durch digitale Pressekonferenzen zu ersetzen. Das ist derzeit sicherlich eine sinnvolle Maßnahme, um neue Produkte und Lösungen zu präsentieren. Aber das Persönliche, ja das Menschliche kommt dabei nur schwer rüber. Ich freue mich daher schon auf die Besuche auf den hoffentlich real stattfindenden Messen und Pressekonferenzen im nächsten Jahr, um so wieder Lkw und mobile Maschinen sowie deren Komponenten anfassen und erleben zu dürfen und direkt mit den Fachleuten ins persönliche Gespräch treten zu können.

Ich wünsche Ihnen viel Spaß beim Lesen der aktuellen Ausgabe der ATZheavyduty. Bleiben Sie gesund.

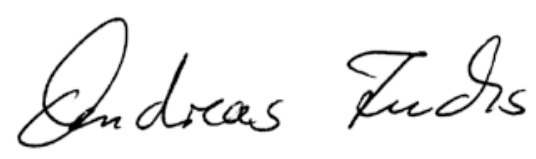

Andreas Fuchs

Verantwortlicher Redakteur

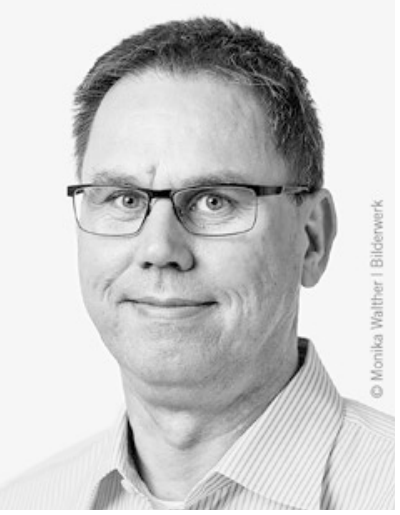

\section{9.-11. NOVEMBER 2021 Messegelände Berlin mobility-electronics.de}

